\title{
PENGARUH DUKUNGAN TEMAN SEBAYA TERHADAP MOTIVASI BELAJAR SISWA KELAS III SEKOLAH DASAR
}

\author{
Novi Nitya Santi ${ }^{1}$, Rosa Imani Khan ${ }^{2}$ \\ nophee.1984@yahoo.com ${ }^{1}$, rossa_rose@unpkediri.ac.id ${ }^{2}$ \\ PGSD, FKIP, UN PGRI Kediri ${ }^{1}$ \\ PG-PAUD, FKIP, UN PGRI Kediri ${ }^{2}$
}

\begin{abstract}
Abstrak: Penelitian ini mengkaji mengenai gambaran motivasi belajar para siswa kelas III SD dan ada atau tidaknya pengaruh dari dukungan teman sebaya terhadap motivasi belajar para siswa kelas III SD tersebut. Pendekatan yang digunakan dalam penelitian ini adalah kuantitatif dengan melibatkan 100 siswa kelas III dari SDN 1, 2 dan 3 Mojoroto Kota Kediri sebagai subyek penelitian. Teknik untuk mengumpulkan data menggunakan angket dan dokumentasi, sedangkan untuk menguji hipotesis dalam penelitian ini menggunakan Uji Krusal-Wallis. Temuan dari penelitian ini antara lain: 1) Motivasi belajar siswa kelas III di SDN 1, 2 dan 3 Mojoroto Kota Kediri tergolong sedang karena mayoritas siswanya, yaitu $40 \%$ atau 40 siswa, memiliki motivasi belajar yang tergolong sedang, 2) Dukungan teman sebaya dapat dikatakan berpengaruh siginifikan terhadap motivasi belajar siswa (probabilitas (sig) < 0,05). Teman sebaya adalah orang di luar anggota keluarga (orang lain) yang memiliki keakraban dengan individu karena seringnya bertemu. Usia mereka relatif sama dan memiliki pemikiran yang sama sehingga menjadi lingkungan kelompok yang dirasa cocok untuk bersosialisasi. Seorang anak bisa memiliki motivasi belajar dan prestasi yang tinggi di sekolahnya jika ia merasa dihargai dan dihormati oleh teman-teman sebayanya.
\end{abstract}

Kata kunci: dukungan teman sebaya, motivasi belajar.

\section{EFFECT OF PEER SUPPORT ON LEARNING MOTIVATION OF THIRD GRADE ELEMENTARY SCHOOL STUDENTS}

\begin{abstract}
This study examines the description of learning motivation of third grade elementary school students and the influence of peer support on the learning motivation of third grade elementary school students. This study uses a quantitative approach with the subject of research as many as 100 third grade students from SDN 1, 2 and 3 Mojoroto Kota Kediri. Data collection techniques in this study used questionnaires and documentation. Testing the hypothesis using the Krusal-Wallis Test. The results of this study found that: 1) The learning motivation of class III students in SDN 1, 2 and 3
\end{abstract}




\section{Novi, Rosa, Pengaruh Dukungan Teman Sebaya...}

Mojoroto Kediri City is included in the medium category because most students, namely $40 \%$ or 40 students, have the motivation to learn the medium category, 2) Friend support peer influence has a significant effect on student learning motivation (probability (sig) $<0.05$ ). Peers are other people outside the family who often meet so that intimacy arises. Their age is relatively parallel and has the same idea so it is a group environment that is suitable for socializing. In the process of education and learning, children will have high motivation and achievement if they feel valued and respected by their peers.

Keywords: peer support, learning motivation.

\section{PENDAHULUAN}

Perkembangan pendidikan bisa menjadi indikator kemajuan sebuah negara. Pendidikan dapat menjadi sarana untuk mewujudkan dan meningkatkan berbagai potensi yang dimiliki oleh manusia. Pendidikan merupakan sebuah usaha yang dilakukan dengan sengaja, teratur dan direncanakan dengan baik oleh pendidik untuk mengubah tingkah laku manusia, baik secara individu maupun kelompok, guna mendewasakan mental manusia tersebut melalui bermacam-macam proses pengajaran dan latihan (Sugihartono, dkk., 2007 dalam Irham\&Wiyani, 2013). Sekolah merupakan sarana dalam rangka mencapai tujuan pendidikan tersebut. Para siswa bisa belajar bermacammacam hal di sekolah. Oleh karena itu, sekolah dapat dikatakan sebagai suatu lembaga formal yang bermanfaat untuk mencetak generasi penerus yang madani.

Melalui kegiatan pembelajaran dalam pendidikan formal, diharapkan peserta didik mengalami perubahan baru yang lebih positif. Diharapkan pula peserta didika akan dapat mengembangkan keterampilan, kemampuan dan pengetahuan yang baru. Prestasi siswa di sekolah merupakan cerminan dari hasil belajar siswa. Untuk mencapai prestasi belajar seperti yang diharapkan oleh guru dan orangtua, diperlukan kegiatan belajar, perhatian dan dukungan orangtua, kinerja guru yang profesional dan motivasi belajar yang tinggi dalam diri siswa. Middleton\&Spanias (1999) menyampaikan bahwa motivasi adalah alasan seorang individu untuk berperilaku dalam situasi tertentu. Motivasi juga berarti kemauan yang ada dalam diri siswa, keinginan, hasrat, dan dorongan untuk aktif dalam kegiatan belajar guna meraih kesuksesaan. Motivasi adalah bagian dari sebuah struktur pencapaian, sebuah keyakinan tentang arti penting dan menentukan jika itu diberi stimulus (Ames, 1992). 
Novi, Rosa, Pengaruh Dukungan Teman Sebaya...

Skinner\&Belmont (1993) mengatakan bahwa jika seorang siswa dirangsang motivasinya untuk mengerjakan tugas di sekolah melalui pemberian tugas yang dapat membangun suasana kompetitif, maka siswa tersebut akan mampu bereaksi sesuai dengan apa yang kita harapkan jika ia diberi kesempatan, dihargai, diberikan situasi dan kondisi yang kondusif untuk berkonsentrasi dalam mengerjakan tugas. Ini berarti bahwa siswa cenderung memiliki emosi yang positif selama kegiatan belajar berlangsung, merasa antusias dan optimis.

Motivasi dan belajar merupakan dua hal yang saling dapat mempengaruhi. Proses belajar adalah proses perubahan perilaku yang relatif permanen dan keberadaannya merupakan hasil dari praktek atau penguatan (reinforced practice) yang didasari maksud untuk meraih tujuan tertentu. Menurtut Logan, dkk. (1976 dalam Tjundjing, 2001), belajar juga dapat diartikan sebagai perubahan perilaku yang relatif menetap yang merupakan hasil dari pengalaman dan latihan. Irwanto (1997) menjelaskan bahwa belajar merupakan proses berubah dari kondisi belum mampu menjadi sudah mampu dan berlangsung dalam jangka waktu tertentu. Motivasi belajar adalah daya dorong guna meraih hasil yang diinginkan, biasanya ditunjukkan dengan tingkah laku belajar atau upaya-upaya untuk meraih tujuan belajar.

Tingkah laku belajar peserta didik begitu dipengaruhi oleh unsur-unsur dari dalam diri dan lingkungan siswa tersebut. Kedua hal itu tidak dapat dipisahkan karena memang proses belajar berlangsung dalam konteks interaksi antara siswa dengan lingkungannya. Itu sebabnya tingkat Sekolah Dasar (SD) kelas 1 sampai 3 dapat dikatakan kelas awal yang kegiatan pembelajarannya menggunakan pendekatan tematik. Pada tahap ini, siswa sudah mulai menunjukkan tingkah laku belajar konkret, sehingga dalam kegiatan pembelajaran tematik tersebut, cocok sekali diterapkan pendidikan karakter yang berkualitas secara integratif dan hierarkis.

Di satu sekolah, bahkan di kelas yang sama, siswa belajar bersama dengan kawankawan sebayanya. Menurut Santrock (2007), teman-teman sebaya (peers) ialah anak-anak atau remaja yang mempunyai usia atau tingkat kematangan yang hampir sama. Adanya teman-teman sebaya ini dapat memberikan dukungan sosial bagi seorang siswa. Ini sejalan dengan penjelasan Hurlock (1999) bahwa teman sebaya dapat menyediakan dukungan sosial yakni berupa rasa senasib yang menjadikan adanya rasa saling mengerti 


\section{Novi, Rosa, Pengaruh Dukungan Teman Sebaya...}

dan memahami masalah masing-masing, saling bertukar nasihat dan simpati. Berkaitan dengan hal tersebut, Cohen\&Syne (2005) mengemukakan bahwa ada beberapa hal yang dapat mempengaruhi efektivitas dari dukungan teman sebaya, antara lain: pemberian dukungan, jenis dukungan, penerimaan dukungan, permasalahan yang dihadapi, waktu pemberian dukungan dan lamanya pemberian dukungan. Dalam realitasnya, guru seringkali mendapatkan kesulitan untuk memotivasi siswa. Misalkan saat siswa sedang merasa jenuh dengan materi atau suasana di kelas, biasanya siswa tersebut akan cenderung ramai sendiri bahkan keluar ruangan. Pada saat seperti itu seyogyanya seorang pendidik yang baik tanggap akan keinginan dan keadaan siswanya. Melihat fenomena tersebut, peneliti tertarik untuk mengkaji mengenai gambaran motivasi belajar para siswa kelas III SD dan ada atau tidaknya pengaruh dari dukungan teman sebaya terhadap motivasi belajar para siswa kelas III SD tersebut.

\section{METODE}

Pendekatan yang digunakan dalam penelitian ini adalah kuantitatif. Pendekatan kuantitatif adalah proses penelitian dengan mengumpulkan data yang berbentuk angka atau data kualitatif yang diangkakan (Sugiyono, 2003). Karakteristik penelitian kuantitatif adalah pengalaman bersifat obyektif dan terukur, realitas hanya satu, yang mempunyai hukum-hukum dan ciri-ciri tertentu yang diselidiki. Dalam penelitian kuantitatif banyak berorientasi pada penggunaan angka, mulai dari pengumpulan data, penafsiran terhadap data, serta pemaparan dari hasil suatu penelitian (Arikunto, 2006). Penelitian ini menggunakan metode survei, yakni penelitian yang mengambil sampel dari sebuah populasi dan menggunakan kuesioner sebagai alat untuk mengumpulkan data pokok (Singarimbun\&Effendi, 1995). Dalam penelitian ini, sampel diambil dengan teknik non random sampling. Masing-masing subyek penelitian diberi angket, diminta mengisinya, kemudian mengembalikan hasilnya. Data-data yang didapat dianalisis sesuai dengan teknik analisis statistik yang sesuai.

Penelitian ini dilakukan di Kelas III SDN I, II dan III Mojoroto Kota Kediri dengan jumlah 100 siswa, yang terdiri dari 53 siswa lak-laki dan 57 siswa perempuan. Data yang diperoleh dalam penelitian ini diolah menggunakan teknik analisis statistik deskriptif dan inferensial. Analisis statistik deskriptif digunakan untuk mengetahui bagaimana 


\section{Novi, Rosa, Pengaruh Dukungan Teman Sebaya...}

motivasi belajar siswa kelas III SD. Sedangkan statistik inferensial digunakan untuk menguji hipotesis. Dalam penelitian ini pengujian hipotesis dilakukan dengan menggunakan Uji Krusal-Wallis untuk mengetahui sejauh mana pengaruh teman sebaya terhadap motivasi belajar siswa kelas III SD.

Instrumen penelitian yang digunakan adalah angket motivasi belajar dan dokumentasi data tingkat pendidikan orangtua. Angket motivasi belajar yang digunakan dalam penelitian ini terdiri dari 25 pertanyaan yang mempunyai empat alternatif jawaban yaitu sangat setuju (SS), setuju (S), kurang setuju (KS) dan tidak setuju (TS).

\section{HASIL dan PEMBAHASAN}

Hasil analisis data yang diperoleh dalam penelitian ini menemukan bahwa siswa yang memiliki motivasi belajar yang termasuk dalam kategori tinggi sebanyak 28 siswa atau $28 \%$, yang termasuk dalam kategori sedang sebanyak 40 siswa atau $40 \%$, dan yang termasuk dalam kategori rendah sebanyak 32 siswa atau 32\%. Motivasi belajar dapat dikatakan sebagai salah satu karakteristik yang mampu mempengaruhi aspek afektif. Semakin seorang siswa memiliki motivasi belajar yang tinggi, maka akan semakin memperhatikan dan berusaha untuk mengingat atas apa yang telah diajarkan oleh guru di sekolah, karena terdapat keyakinan dalam dirinya bahwa semua ilmu itu kelak akan berguna untuk mencapai cita-citanya.

Hasil uji peringkat Kruskal-Wallis menunjukkan bahwa nilai Mean Rank antara dukungan teman sebaya yang mempengaruhi motivasi sebesar 80,79, sehingga motivasi belajar tinggi didukung oleh keberadaan teman sebaya. Kelompok teman-teman sebaya menyediakan suatu lingkungan, yaitu tempat untuk melakukan sosialisasi dengan nilai yang berlaku pada usia sebayanya, bukan nilai yang ditetapkan oleh orang-orang dewasa di sekitarnya. Kelompok teman-teman sebaya juga bisa menjadi tempat untuk membantu individu menemukan seperti apa jati dirinya tanpa adanya tekanan dari orang dewasa. Penjelasan ini sejalan dengan pendapat Laursen (2005) yang menjelaskan bahwa kelompok teman-teman sebaya yang kondusif membuat remaja merasa diterima, melakukan katarsis, dan menguji nilai-nilai dan pandangan-pandangan baru dalam

hidupnya. Lebih lanjut, Laursen (2005) menegaskan bahwa kelompok teman sebaya yang positif mampu memberikan kesempatan kepada remaja untuk membantu orang lain 


\section{Novi, Rosa, Pengaruh Dukungan Teman Sebaya...}

dan memperluas jaringan kerja untuk saling memberikan dukungan positif. Selain itu kelompok teman sebaya yang positif juga akan menyediakan kesempatan kepada seorang remaja untuk menguji keefektivan komunikasi, perilaku, persepsi, dan nilai-nilai hidup yang mereka miliki. Kelompok teman sebaya yang kondusif akan sangat membantu seorang remaja untuk mengerti bahwa dia tidak sendirian dalam menghadapi berbagai tantangan hidup.

Keberadaan dukungan dari teman-teman sebaya dapat membantu atau memberikan keuntungan kepada anak-anak yang mempunyai masalah sosial dan keluarga, dapat membantu memperbaiki suasana sekolah, dan menyediakan tempat untuk berlatih keterampilan sosial. Tetapi tidak semua teman sebaya dapat menguntungkan perilaku belajar anak. Perkembangan individu akan terbantu jika ia mempunyai temanteman sebaya yang terampil secara sosial dan bersifat mendukung. Sedangkan temanteman sebaya yang seringkali memaksakan kehendak dan memicu konflik akan menghambat tingkah laku belajar anak. Terpengaruh atau tidaknya individu dengan teman-teman sebayanya tergantung pada pemikiran individu tersebut terhadap kelompoknya. Persepsi individu terhadap teman-teman sebayanya akan mempengaruhi keputusan apa yang akan dia ambil nantinya.

Kegiatan anak bersama dengan kawan-kawan sebayanya memang memiliki pengaruh yang baik untuk perkembangannya. Tetapi jika nilai yang dikembangkan dalam kelompok teman-teman sebayanya adalah nilai yang negatif maka akan menimbulkan bahaya bagi perkembangan jiwa anak yang akan berpengaruh pada proses belajar anak. Jika anak terlalu banyak melakukan kegiatan bersama dengan kawan-kawan sebayanya, sedangkan dia tidak bisa membagi waktu belajarnya, maka kegiatan tersebut akan merugikan anak karena aktivitas belajarnya dapat terganggu.

Hubungan yang baik di antara anggota kelompok kawan-kawan sebaya akan dapat membantu perkembangan aspek sosial anak secara wajar dan akan berpengaruh pada proses belajar anak di sekolah. Anak pemalu yang ditolak oleh kawan sebayanya lalu merasa kesepian, akan beresiko mengalami depresi. Anak yang agresif terhadap kawan sebayanya, beresiko pada munculnya sejumlah masalah seperti kenakalan dan drop out dari sekolah. Dalam jalinan interaksi antar sebaya, memungkinkan terjadinya proses identifikasi, kerjasama dan kolaborasi. Hal-hal tersebut akan mewarnai proses 


\section{Novi, Rosa, Pengaruh Dukungan Teman Sebaya...}

terbentuknya perilaku dan proses belajar anak. Melihat betapa pentingnya peran teman sebaya tersebut, maka pembentukan dan pengembangan lingkungan teman sebaya yang positif merupakan cara efektif yang dapat dilakukan untuk meningkatkan motivasi belajar seorang siswa.

\section{SIMPULAN}

Dari temuan-temuan yang didapat oleh penelitian ini dapat disimpulkan bahwa rata-rata siswa kelas III SDN I, II dan III Mojoroto Kota Kediri memiliki motivasi belajar yang berada dalam kategori sedang. Dukungan teman sebaya mempunyai peran yang penting terhadap motivasi belajar siswa di sana. Dukungan teman sebaya mempunyai beberapa peran dalam pembentukan motivasi belajar yang tinggi, diantaranya adalah sebagai pemenuh the needs of affection atau kebutuhan afeksi yang berupa kebutuhan individu akan kasih sayang, perhatian dan penerimaan. Selain itu, dukungan teman sebaya juga berperan sebagai penyedia motivasi yaitu memberikan dorongan untuk melakukan sesuatu yang belum dilakukan atau dorongan untuk melakukan sesuatu dengan baik termasuk untuk rajin belajar.

\section{UCAPAN TERIMA KASIH}

Dalam menyelesaikan penelitian ini, peneliti didukung oleh banyak pihak. Maka pada kesempatan ini, peneliti ingin menyampaikan ucapan terima kasih yang sebesarbesarnya kepada yang saya hormati:

1. Seluruh Dewan Redaksi dan Panitia Penyelengga Jurnal Pendidikan Dasar Nusantara

2. Rektor Universitas Nusantara PGRI Kediri

3. Dekan FKIP Universitas Nusantara PGRI Kediri

4. Ketua Prodi. PGSD dan PG-PAUD Universitas Nusantara PGRI Kediri beserta seluruh dosen Prodi. PGSD dan PG-PAUD selaku rekan sejawat peneliti

5. Kepala Sekolah SDN I, II, III Mojoroto Kota Kediri beserta seluruh guru, khususnya wali kelas dan guru kelas III

Terima kasih kepada seluruh pihak yang telah mendukung terselesaikannya penelitian ini. 
Novi, Rosa, Pengaruh Dukungan Teman Sebaya...

\section{DAFTAR RUJUKAN}

Ames, C. 1992. Classroom: Goals, Structures, and Student Motivation. Journal of Education Psychology, 84 (3): 261-271.

Arikunto, Suharsimi. 2006. Prosedur Penelitian Suatu Pendekatan Praktik. Jakarta: Rineka Cipta.

Cohen, S. \& S.I. Syne. 2005. Social Support and Health. London: Academic Press Inc.

Hurlock, Elizabeth B. 1999. Perkembangan Anak, Jilid 2. Jakarta: Erlangga.

Irham, Muhamad \& Novan Ardy Wiyani. 2013. Psikologi Pendidikan. Teori dan Aplikasi dalam Proses Pembelajaran. Jogjakarta : Ar-Ruzz Media.

Irwanto. 1997. Psikologi Umum. Jakarta: Gramedia.

Laursen, E.K. 2005. Rather Than Fixing Kids - Build Positive Peer Cultures. Reclaiming Children and Youth. ProQuest Education Journals, 12 (3): 137-142.

Middleton, James A. \& Photini A. Spanias. 1999. Motivation for Achievement in Mathematics: Findings, Generalizations, and Criticisms of The Research. Journal for Research in Mathematics Education, 30 (1): 65-88.

Santrock. 2007. Remaja, Edisi 11 Jilid 2. Jakarta: Erlangga.

Singarimbun, Masri \& Sofyan Effendi. 1995. Metode Penelitian Survei, Edisi Revisi. Jakarta: Pustaka LP3ES.

Skinner, E.A. \& M.J. Belmont. 1993. Motivation in Classroom: Reciprocal Effects of Teacher Behavior and Student Engagement Across The School Year, Journal of Educational Psychology, 85 (4): 571-581.

Sugiyono. 2003. Metode Penelitian Kuantitatif, Kualitatif, dan R\&D. Bandung: Alfabeta..

Tjundjing, Sia. 2001. Hubungan antara IQ, EQ, dan QA dengan Prestasi. Studi pada Siswa SMU. Jurnal Anima, 17 (1) 